\title{
Potential Impact of Load Curtailment on the Day-ahead Iberian Market: A Preliminary Analysis
}

\author{
Francisco Rodrigues ${ }^{1}$, Hugo Algarvio ${ }^{2,3, \star}$, Fernando Lopes ${ }^{2}$, Anabela Pronto ${ }^{1}$ \\ and João Santana ${ }^{3,4, \star}$ \\ 1 Faculdade de Ciências e Tecnologia, Universidade Nova de Lisboa, Lisboa, Portugal \\ \{fad.rodrigues@campus.fct.unl.pt, amg1@fct.unl.pt\} \\ 2 LNEG-National Research Institute, Est. do Paço do Lumiar 22, Lisboa, Portugal \\ fernando.lopes@lneg.pt \\ 3 Instituto Superior Técnico, Avenida Rovisco Pais 1, Lisboa, Portugal \\ \{hugo.algarvio, jsantana\}@tecnico.ulisboa.pt \\ 4 INESC-ID, Rua Alves Redol 9, Lisboa, Portugal
}

\begin{abstract}
Demand response (DR) in electricity markets may offer a variety of financial and operational benefits. Typically, customers respond to DR events by adopting curtailment and shifting strategies. This article focuses on the former strategy and assumes that consumers are encouraged to avoid consuming electricity during specific hours of a 24 hour day, because the energy price is above a given threshold. It presents a study on the Iberian market, conducted with the help of an agent-based simulation tool, called MATREM. The results are very favorable to the adoption of the load curtailment strategy (as a consequence of the enrollment in different DR programs).
\end{abstract}

Keywords: Electricity markets; MIBEL; demand response; load curtailment; the MATREM system.

\section{Introduction}

All over the world and especially in the European Union (EU), the restructuration of the electricity industry has contributed to the growth and development of many regional markets $[1,2]$. In particular, the Iberian Electricity market (MIBEL) has emerged from the cooperation between two member countries, Portugal and Spain, with the goal of integrating the electrical systems of both countries, reducing the problems associated with the process of interchanging electricity. One of the main goals of MIBEL is the free access and competition in the supply industry of electrical energy, requiring competitors to follow specific rules and behave in a transparent way regarding their objectives and market negotiations $[3,4]$.

\footnotetext{
* This work was supported by "Fundação para a Ciência e Tecnologia" with references UID/CEC/50021/2013 and PD/BD/105863/2014 (H. Algarvio).
} 
With the implementation of MIBEL, a problem emerged, evidenced by the disconnection between the retail and wholesale markets, where consumers instead of "seeing" the price of electricity as something dynamic and changing on a hourly basis, "view" a static value, discouraging them from changing their consumption patterns (during periods of high market prices). Without such important changes that could happen in the demand side, the wholesale market is to some extent deprived of defenses against the high volatility of prices (inherent to the sale and purchase of electricity), giving market power to generating companies and benefiting them in the short-term to negotiate the electricity prices at high values. All of these could be avoided, at least in part, with the implementation of demand response programs $[5,6]$.

Demand response (DR) can be defined as a process where end-use customers of electricity, due to the changing prices, modify their usage values through changes in their daily energy consumption patterns. An interesting possibility to introduce this concept in the mind of energy consumers spins around some demand response programs that shift the market power to the hands of end-user customers, and most importantly, give them the choice to use the advantage of being part of an open market. DR programs can be divided into the following two categories [7]:

1. Incentive-based programs: rely on agreements between consumers and market entities, where it is expected that the first party responds to requests made by the second party, in critical hours, being rewarded economically when they do that, and suffering penalties when they fail to do that. Examples include direct load control and interruptible/curtailment agreements.

2. Price-based programs: rely on the implementation of time-varying tariffs involving a dynamic price for electricity, so that consumers can adjust their patterns of consumption. Examples include time-of-use (TOU) rates and Real-time pricing (RTP) rates.

In the EU, the inclusion of demand response in regional markets has been accomplished with the signing of various agreements, and consequently the drafting of a number of laws, the most important being the one celebrated in Paris, where it was decided that all the resources associated with DR should be used in order to obtain competitive prices, stimulating the markets to innovate, and encouraging consumers to participate.

Although some countries are proving that the implementation of DR programs is not impossible, the progress has been slow, in part due to a lack of "education" that consumers have towards this concept, and also because of the short and long-term investments that are needed in order to make these programs feasible. France is a country where the implementation of DR programs has been successful. At the time of writing, the concept of DR is implemented and fully operational - or pilot projects are ongoing - in all the sectors of the French electricity market, ranging from the wholesale market and the network services of distribution to the reserve and auxiliary mechanisms used in critical situations [8]. 
As for the Iberian electricity market, Spain has shown more progress than Portugal. Worthy to mention is the nationwide implementation of smart-meters, a form of consumers being informed of the real time-pricing of electricity and giving them more control of their household appliances $[8,9]$.

Customers respond to DR events by adopting several basic load response strategies, notably shifting and curtailment [7]. This article focuses on the load curtailment strategy and considers that consumers are encouraged to avoid consuming electricity during specific hours of a 24 hour day, because the energy price is above a given threshold. More specifically, the article considers different levels of demand response, modeled as load reductions between $1 \%$ and $5 \%$ when prices rise above a threshold between 80 and $100 € / M W h$. The main goal of the article consists of analyzing the potential benefits of the load curtailment strategy for all participants of the Iberian market, namely to determine the price reductions in critical periods and to quantify the financial benefits. To this end, it presents a study on MIBEL, conducted with the help of an agent-based simulation tool, called MATREM (for Multi-agent TRading in Electricity Markets).

This article builds on our previous work in the area of demand response and energy markets. In particular, Lopes and Algarvio [9] investigated the impact of different levels of DR on the Iberian market prices, and analyzed the potential benefits for market participants and retail customers. Demand response was modeled as modest load reductions (between 1\% and 5\%) at times of high market prices (i.e., when prices rose above a threshold between 80 and $100 € / \mathrm{MWh}$ ). The period under consideration ranged between January 1, 2014 and June 30, 2017. This article extends our previous study by considering the following 18month period: January 1, 2017 to June 30, 2018.

Now, there are other pieces of work that analyzed the potential effect of demand response on the Iberian market prices, notably Fernández et al. [10]. However, the authors did not consider price thresholds, meaning that all hours of the period of the study were considered (from April 2014 to March 2015) that is, the study considers load reductions of $1.5 \%, 3 \%$ and $6 \%$ uniform for all hours of a 24-hour day. In this way, and despite being a very detailed study, we believe that it does not represent very well practical situations (in terms of possible implementation in the real-world by end-use customers).

The remainder of this paper is structured as follows. Section 2 presents a brief overview of the MATREM system. Section 3 presents the case study and

discusses the simulation results. Finally, section 4 states the conclusions and outlines some avenues for future work.

\section{Overview of the MATREM System}

MATREM allows the user to conduct a wide range of simulations regarding the behaviour of electricity markets under a variety of conditions (see [11] for a detailed description of the system and [12] for its classification according to a number of dimensions related to both competitive energy markets and software agents). 
MATREM supports a day-ahead market and a shorter-term market known as intraday market. Supply bids and demand offers are aggregated to find a clearing price at which supply and demand are equal (see, e.g., [13]). MATREM is also able to simulate a balancing market. The system operator defines the needs of this market and generating company agents may submit bids to buy or sell energy (see, e.g., [14]).

Furthermore, MATREM supports a derivatives exchange comprising a futures market for trading standardized bilateral contracts, and a marketplace for negotiating the details of tailored (or customized) long-term bilateral contracts (see, e.g., [15]). To this end, buyer and seller agents are equipped with a negotiation model that handles two-party and multi-issue negotiation (see, e.g., [16]). In short, the negotiation process involves three main phases or stages, namely pre-negotiation (focuses on preparation and planning for negotiation), actual negotiation (seeks a solution for a dispute and is characterized by movement toward a mutually acceptable agreement), and post-negotiation (centers on details and implementation of a final agreement).

Currently, MATREM considers six key types of market entities: generating companies, retailers, aggregators, consumers, market operators and system operators. Also, the tool considers two key types of software agents: market agents and assistant agents. Market agents represent the entities that take part in the various simulated markets. Assistant agents are categorized into interface managers (responsible for managing the interfaces of the simulated markets) and intelligent assistants (provide support to the user in making strategic decisions). The agents are being developed using the JAVA Agent Development Framework (JADE), an open source platform for peer-to-peer agent based applications [17]. The target platform for the system is a 32/64-bit computer running Microsoft Windows.

\section{Case Study}

The purpose of this study is to investigate the effects of different levels of demand response on the daily prices of the Iberian market and analyze the potential benefits that result to market participants and retail customers. The following sources of data are considered $[18,19]$ : (i) day-ahead prices and energy quantities submitted to MIBEL, and (ii) market-clearing prices and energy quantities traded in MIBEL. ${ }^{5}$

The experimental method involves basically the following: (i) to simulate the day-ahead markets prices actually observed in MIBEL, (ii) to simulate the dayahead market prices in the presence of of specific levels of demand response, and (iii) to compute the effect on market price (estimated as the difference between the prices calculated in the two previous items).

\footnotetext{
5 This study extends our previous study about the impact of different levels of DR on the Iberian market prices [9], by considering the second half of 2017 and the first half of 2018. The software agents, method, and energy scenarios are essential identical in both studies, and details are therefore omitted.
} 
Table 1. Average monthly price reductions

\begin{tabular}{ccc}
\hline \multirow{2}{*}{ Scenario } & \multicolumn{2}{c}{ Average Price Reduction $(€ / \mathrm{MWh})$} \\
\cline { 2 - 3 } & \multicolumn{2}{c}{ Year 2017 } \\
\cline { 2 - 3 } & January & December \\
\hline B1 & 1.11 & 1.09 \\
B2 & 3.45 & 2.90 \\
B3 & 6.06 & 4.43 \\
C1 & 1.04 & 0.84 \\
C2 & 3.57 & 1.77 \\
C3 & 6.85 & 2.86 \\
D1 & 0.39 & - \\
D2 & 1.64 & - \\
D3 & 2.76 & - \\
\hline
\end{tabular}

The following ten scenarios for electricity consumption are considered:

- Scenario A (base-case scenario): the simulations are performed in order to reproduce the market prices reported by MIBEL;

- Scenarios B1-B3, C1-C3, D1-D3: to simulate what would have been the market prices in the presence of specific levels of DR, the values of the electricity demand are changed correspondingly (the letters indicate a specific threshold price, namely 80,90 or $100 € /$ MWh respectively, and the numbers represent a particular level of DR, namely $1 \%, 3 \%$ or $5 \%$ respectively).

The time period of the study has the duration of 18 months: from January 1, 2017 to June 30, 2018.

The analysis is carried out using the MATREM system. The number of agents representing the electricity supply industry varies between 50 and 200. The demand for electrical energy is assumed to be perfectly inelastic, meaning that a single agent bids the entire demand at a price of $180 € / \mathrm{MWh}$. To represent the Iberian market in a realistic way, the study takes in account the hours where the phenomenon of market-splitting occurs. In such hours, MATREM simulates the Portuguese region only. In the remaining hours, MATREM simulates the market prices for both Portugal and Spain. There are 978 DR events in the period under consideration (interestingly, all events occurred in the year 2017).

Tables 1 and 2 summarize the results of the study. The values shown in Table 1 represent the average monthly price reductions. As expected, the price reductions increase with larger levels of DR, regardless of the threshold price. For scenario B3 (corresponding to a load reduction of $5 \%$ and a threshold price of $80 € / \mathrm{MWh}$ ), the price reduction in January reaches $6.06 € / \mathrm{MWh}$, decreasing to $4.43 € / \mathrm{MWh}$ in December. For scenarios C1-C3, the largest price reduction occurs in January $(6.85 € /$ MWh in scenario C3, corresponding to a load reduction of $5 \%$ and a threshold price of $90 € / \mathrm{MWh})$. In December, the price reduction reaches $2.86 € / \mathrm{MWh}$ only. 
Table 2. Financial benefits of "demand response"

\begin{tabular}{ccc}
\hline Scenario & $\begin{array}{c}\text { Market Value of Energy } \\
(\text { million } €)\end{array}$ & $\begin{array}{c}\text { Load Curtailment Benefit } \\
(\text { million } €)\end{array}$ \\
\cline { 2 - 3 } & 2017 & 2017 \\
\hline B1 & 677.45 & 16.08 \\
B2 & 646.02 & 47.51 \\
B3 & 614.58 & 78.95 \\
C1 & 298.85 & 6.51 \\
C2 & 284.64 & 20.71 \\
C3 & 268.49 & 36.87 \\
D1 & 12.04 & 0.17 \\
D2 & 11.65 & 0.56 \\
D3 & 11.28 & 0.93 \\
\hline
\end{tabular}

Table 2 shows the market value of energy during the time period of the study (considering the hours corresponding to DR events only). As expected, this value decreases with an increase of either the level of DR or the threshold price. For scenario B1, the market value of energy reaches the highest value (677.45 million $€)$. And for scenario D3, it reaches the lowest value (11.28 million $€$ ). For scenarios B1 and B3, the difference between the corresponding market values of energy is 62.87 million $€$, decreasing to 30.36 million $€$ for scenarios $\mathrm{C} 1$ and $\mathrm{C} 3$, and to 0.76 million $€$ for scenarios D1 and D3. This can explained, at least in part, by the reduced occurrence of DR events in the scenarios corresponding to higher threshold prices.

Table 2 also shows the potential benefit of the load curtailment strategy. The results are very interesting, indicating that the adoption of this strategy (as a result of the enrollment in DR programs), is indeed beneficial to market participants and retail customers. For the particular case of scenario B3, the benefit of doing a small curtailment of load $(5 \%)$ reaches the value of 78.95 million $€$, a considerable monetary value. Is also important to observe the result of scenario D3 - involving 3 DR events only, occurring on 25 January 2017 (and corresponding to market prices $\geq 100 € / \mathrm{MWh}$ ) - where the financial benefit reaches almost 1 million $€$. Therefore, and in short, the adoption of the load curtailment strategy by end-use customers can be considered a very important aspect for the market sector, resulting in a win-win situation.

\section{Conclusion}

This paper has given an overview of the agent-based simulation tool for electricity markets, called MATREM, currently under development. It has also presented a study to investigate the impact of different levels of load curtailment on the daily prices of MIBEL and analyze the potential benefits that result to all participants. 
The impacts of the load curtailment strategy on the Iberian market prices can be summarized as follows:

- In 2017, the annual price reduction ranged from $0.39 € / \mathrm{MWh}$ to $6.76 € / \mathrm{MWh}$ (a decline ranging from $0.39 \%$ to $7.22 \%$ ). These values can be explained, at least in part, by the slope of the supply curve, especially in January (a month associated with more than 200 DR events, corresponding to scenarios B1-B3).

- In 2017, the financial benefits of the load curtailment strategy (or indirectly, the benefits of demand response) are very interesting, reaching the considerable value of 78.95 million $€$. This is probably due to the high number of DR events that occurred in this year.

- In the first half of 2018 (181 days), there were no DR events (since the market price was always below $80 € / \mathrm{MWh})$.

These results are very favorable to the adoption of the load curtailment strategy, as a consequence of the enrollment in different DR programs, since modest load curtailments (1\% to 5\%) led to substantial reductions of market prices and considerable financial benefits.

\section{References}

1. Stoft, S.: Power Systyem Economis - Designing Markets for Electricity. IEEE Press and Wiley Interscience (2002)

2. Lopes, F., Coelho, H.: Electricity Markets with Increasing Levels of Renewable Generation: Structure, Operation, Agent-based Simulation and Emerging Designs. Springer, Cham (2018) https://doi.org/10.1007/978-3-319-74263-2

3. OMIE: Day-ahead and Intraday Electricity Market Operating Rules (May 2018) http://www.omie.es/files/market_rules_2018.pdf (Cited on 02 April, 2018)

4. OMIP: Trading RuleBook. MIBEL Derivatives Market, Lisbon, Portugal (2016)

5. Braithwait, S., Eakin, K., Inc., Laurits R. Christensen A.: The Role of Demand Response in Electric Power Market Design. Technical Report, Edison Electric Institute, Washington, D.C. (October 2002)

6. FERC: Assessment of Demand Response and Advance Metering. Staff Report of the Federal Energy Regulatory Commission, Washington, D.C. (December 2015)

7. DOE: Benefits of Demand Response in Electricity Markets and Recommendations for Achieving Them. A Report to the United States Congress Pursuant to Section 1252 of the Energy Policy Act of 2005, US Department of Energy (February 2006)

8. SEDC: Explicit Demand Response in Europe: Mapping the Markets 2017. Report of the Smart Energy Demand Coalition, Brussels, Belgium (2017)

9. Lopes, F., Algarvio, H.: Demand Response in Electricity Markets: An Overview and a Study of the Price-Effect on the Iberian Daily Market. In: Electricity Markets with Increasing Levels of Renewable Generation: Structure, Operation, Agentbased Simulation, and Emerging Designs, pp. 265-303, Springer, Cham (2018) https://doi.org/10.1007/978-3-319-74263-2_10

10. Fernández, J., Payán, M., Santos, J., García, A.: The Voluntary Price for the Small Consumer: Real-time Pricing in Spain. Energy Policy 102, 41-51 (2017) 
11. Lopes, F.: MATREM: An Agent-based Simulation Tool for Electricity Markets. In: Electricity Markets with Increasing Levels of Renewable Generation: Structure, Operation, Agent-based Simulation and Emerging Designs, pp. 189-225, Springer, Cham (2018) https://doi.org/10.1007/978-3-319-74263-2_8

12. Lopes, F., Coelho, H.: Electricity Markets and Intelligent Agents. Part II: Agent Architectures and Capabilities. In: Electricity Markets with Increasing Levels of Renewable Generation: Structure, Operation, Agent-based Simulation and Emerging Designs, pp. 49-77, Springer, Cham (2018) https://doi.org/10.1007/ 978-3-319-74263-2_3

13. Lopes, F., Sá, J., Santana, J.: Renewable Generation, Support Policies and the Merit Order Effect: A Comprehensive Overview and the Case of Wind Power in Portugal. In: Electricity Markets with Increasing Levels of Renewable Generation: Structure, Operation, Agent-based Simulation and Emerging Designs, pp. 227-263, Springer, Cham (2018) https://doi.org/10.1007/978-3-319-74263-2_9

14. Algarvio H., Lopes F., Couto A., Estanqueiro A.: Participation of Wind Power Producers in Day-ahead and Balancing Markets: An Overview and a Simulationbased Study. WIREs Energy and Environment (2019) https://doi.org/10.1002/ wene. 343

15. Lopes, F., Algarvio, H., Santana, J.: Agent-based Simulation of Electricity Markets: Risk Management and Contracts for Difference. In: Agent-based Modelling of Sustainable Behaviors, pp. 207-225, Springer, Cham (2017) https://doi.org/ 10.1007/978-3-319-46331-5_10

16. Lopes, F., Mamede, N., Novais, A. Q., Coelho, H.: A Negotiation Model for Autonomous Computational Agents: Formal Description and Empirical Evaluation, Journal of Intelligent \& Fuzzy Systems 12, pp. 195-212, 2002.

17. Bellifemine, F., Caire, G., Greenwood, D.: Developing Multi-agent Systems with JADE. John Wiley \& Sons, Chichester (2007)

18. OMIE: "Operador del Mercado Ibérico de Energía (Spanish Electricity Market Operator)." Market Results (online data)

http://www.omie.es/files/flash/ResultadosMercado.swf (Cited on 02 Abril, 2019)

19. REN: Redes Energéticas Nacionais, Preços Mercado Spot, Portugal e Espanha. http://www.mercado.ren.pt/PT/Electr/InfoMercado/InfOp/MercOmel/ Paginas/Precos.aspx (Cited on 02 Abril 2019) 